\title{
The complementary role of liability and safety regulation
}

This is the peer reviewed version of the following article:

Original:

D'Antoni, M., \& Tabbach Avraham, D. (2019). The complementary role of liability and safety regulation. AMERICAN LAW AND ECONOMICS REVIEW, 21(1), 150-183 [10.1093/aler/ahz001].

Availability:

This version is availablehttp://hdl.handle.net/11365/1093805.8 since 2020-02-21T16:57:47Z

\section{Published:}

DOI:10.1093/aler/ahz001

Terms of use:

Open Access

The terms and conditions for the reuse of this version of the manuscript are specified in the publishing policy. Works made available under a Creative Commons license can be used according to the terms and conditions of said license.

For all terms of use and more information see the publisher's website.

(Article begins on next page) 
J_ID: aler Cust. A_ID: 00000.00 Cadmus Art: aler00000 CVO ID:

OP-ALEC190001 - 2019/1/31 - page 1 - \#1

\section{Author Queries}

AQ1: Please check that all names have been spelled correctly and appear in the correct order. Please also check that all initials are present. Please check that the author surnames (family name) have been correctly identified by a pink background. If this is incorrect, please identify the full surname of the relevant authors. Occasionally, the distinction between surnames and forenames can be ambiguous, and this is to ensure that the authors' full surnames and forenames are tagged correctly, for accurate indexing online. Please also check all author affiliations.

AQ2: Please provide the complete address for corresponding author.

AQ3: Please provide the publisher location for Cooter, Robert and Thomas Ulen (2008).

AQ4: Please provide the page range for Kritzer, Herbert (1998).

AQ5: Figures have been placed as close as possible to their first citation. Please check that they have no missing sections and that the correct figure legend is present.

AQ6: Please check that the text is complete and that all figures, tables and their legends are included.

AQ7: Please check that special characters, equations, dosages and units, if applicable, have been reproduced accurately.

AQ8: Please provide a Funding statement, detailing any funding received. Remember that any funding used while completing this work should be highlighted in a separate Funding section. Please ensure that you use the full official name of the funding body, and if your paper has received funding from any institution, such as NIH, please inform us of the grant number to go into the funding section. We use the institution names to tag NIH-funded articles so they are deposited at PMC. If we already have this information, we will have tagged it and it will appear as coloured text in the funding paragraph. Please check the information is correct. 
J_ID: aler Cust. A_ID: 00000.00 Cadmus Art: aler00000 CVO ID:

OP-ALEC190001 - 2019/1/31 - page 0 - \#2

MAKING CORRECTIONS TO YOUR PROOF

These instructions show you how to mark changes or add notes to your proofs using Adobe Acrobat Professional versions 7 and onwards, or Adobe Reader DC. To check what version you are using go to Help then About. The latest version of Adobe Reader is available for free from get.adobe.com/reader.

\section{DISPLAYING THE TOOLBARS}

Adobe Reader DC

In Adobe Reader DC, the Comment toolbar can be found by clicking 'Comment' in the menu on the right-hand side of the page (shown below).

$$
\begin{aligned}
& {[\rightarrow \text { Export PDF V }} \\
& \text { 든 Create PDF v } \\
& \begin{array}{l}
\square \equiv \text { Edit PDF } \\
\ominus \text { Comment }
\end{array} \\
& \text { 땐 Combine Files v } \\
& \text { Qu Fill \& Sign } \\
& \underline{x h} \text { Send for Signature } \\
& \rightarrow \cdots \text { Send \& Track }
\end{aligned}
$$

\begin{tabular}{|c|c|}
\hline 3 comment . & \\
\hline$\equiv$ Add Sticky Note & Ctrl +6 \\
\hline Show Comment \& Markup Toolbar & \\
\hline Show Comments List & ho \\
\hline $\begin{array}{l}\text { Attach for Émail Review... } \\
\text { Track Reviews... }\end{array}$ & \\
\hline
\end{tabular}

The toolbar shown below will then display along the top.

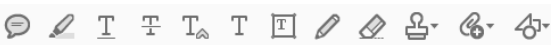

Acrobat Professional 7, 8, and 9

In Adobe Professional, the Comment toolbar can be found by clicking 'Comment(s)' in the top toolbar, and then clicking 'Show Comment \& Markup Toolbar' (shown below).

\begin{tabular}{|c|c|}
\hline F Text Edits & 国 \\
\hline \multicolumn{2}{|l|}{ IT Iext Edits Tool } \\
\hline 国 Replace Selected Text & \\
\hline (T) Highlight Selected Text & \\
\hline 7) Add Note To Selected Text & \\
\hline T. Insert Text At Cursor & \\
\hline$\underline{\text { T] }} \underline{\text { Underline Selected Text }}$ & \\
\hline$\boxplus$ Cross Out Text for Deletion & \\
\hline
\end{tabular}

The toolbar shown below will then be displayed along the top

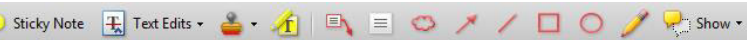

USING TEXT EDITS AND COMMENTS IN ACROBAT

This is the quickest, simplest and easiest method both to make corrections, and for your corrections to be transferred and checked.

\section{Click Text Edits}

2. Select the text to be annotated or place your cursor at the insertion point and start typing.

3. Click the Text Edits drop down arrow and select the required action.

You can also right click on selected text for a range of commenting options, or add sticky notes.

\section{SAVING COMMENTS}

In order to save your comments and notes, you need to save the file (File, Save) when you close the document.
USING COMMENTING TOOLS IN ADOBE READER

All commenting tools are displayed in the toolbar. You cannot use text edits, however you can still use highlighter, sticky notes, and a variety of insert/replace text options.

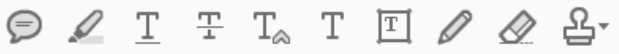

\section{POP-UP NOTES}

In both Reader and Acrobat, when you insert or edit text a pop-up box will appear. In Acrobat it looks like this:

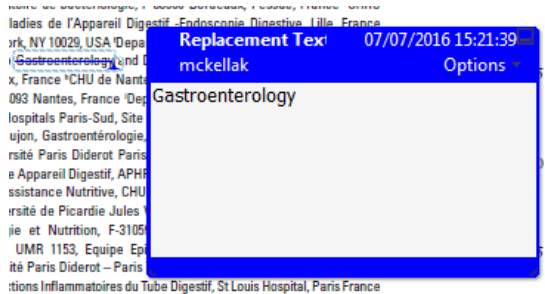

In Reader it looks like this, and will appear in the right-hand pane: Page 1

mckellak

$\mathrm{T}_{\infty}$ Inserted Text

21/07/2016 12:03

please insert comma here

DO NOT MAKE ANY EDITS DIRECTLY INTO THE TEXT, USE COMMENTING TOOLS ONLY. 
J_ID: aler Cust. A_ID: 00000.00 Cadmus Art: aler00000 CVO ID:

OP-ALEC190001 - 2019/1/31 - page 1 - \#3

\section{The Complementary Role of Liability and Safety Regulation}

Massimo D'Antoni University of Siena, and Avraham D. Tabbach Tel-Aviv University

Send correspondence to: Massimo D’Antoni, University of Siena; Email: DANTONI@unisi.it

This article deals with the control of hazardous activities in situations where potential victims can affect their exposure to risk. Economists have generally considered ex ante regulation (safety standards) to be a substitute for ex post policies (exposure to tort liability) in order to control externalities. We show that when the victim's compensation is partial (e.g., due to death or serious bodily injury) there are inefficiencies associated with the exclusive use of negligence liability and that an optimal policy may involve the combined use of ex-ante regulation and ex-post liability. A noteworthy feature of our explanation is that regulation is complementary to liability, in the sense that it may facilitate a higher and more efficient standard of negligence. In that case, it is efficient to set the regulatory safety standard below the standard of negligence, which is consistent with the legal doctrines of negligence per se and the (non) regulatory compliance defense. (JEL: K13, K23)

\section{Introduction}

One of the main issues debated in the economics literature on the control of externalities is the choice between ex-ante regulation of risky behavior and ex-post tort liability for its consequences (henceforth "regulation" and "liability," respectively). In an ideal setting, either regulation or liability can

We thank Abraham Wickelgren, two anonymous referees, and the participants to the 2016 Siena/Toronto/Tel-Aviv Workshop on Law and Economics and to the 2017 Conference of the European Law and Economics Association, for their valuable comments and suggestions on earlier versions of the article.

American Law and Economics Review

doi:10.1093/aler/ahz001

(C) The Author 2019. Published by Oxford University Press on behalf of the American Law and Economics Association. All rights reserved. For permissions, please e-mail: journals.permissions@oup.com 
induce efficiency. However, when information is limited, adequate sanctions cannot be imposed or administration costs are taken into account, the two instruments can produce different outcomes in terms of efficiency. In these circumstances, economic analysis can identify which of the these two instruments is better suited to minimize social costs.

It has been pointed out, for example, that liability is more vulnerable in the following scenarios: the judgment-proof problem (i.e., the possibility that the injurer will go bankrupt and will not be able to compensate the victim); the possibility that only some of the victims will be successful in obtaining compensation; the difficulty or impossibility of identifying the injurer, especially if the effects of the externality are long-term; or the possibility that injurers will not be fully aware of the consequences of their actions. On the other hand, regulation is usually constrained by limited information, and because the regulator does not take into account specific circumstances. As a result, regulation will under-deter some injurers and over-deter others. Moreover, regulation is generally considered to be more costly to enforce because it requires monitoring of behavior rather than accidents (Shavell, 2013). ${ }^{1}$ Therefore, the social preferability of either regulation or liability cannot be determined for the general case, but rather depends on the specific situation under consideration.

While the pros and cons of each instrument are well understood, what seems to generate less agreement is the reason that regulation and liability are so often used jointly. For example, in the United States, the Resource Conservation and Recovery Act (1982) imposes technological regulations on the production of toxic wastes, while under the Comprehensive Environmental Response, Compensation, and Liability Act (1979) victims can sue hazardous waste producers for the recovery of compensatory and punitive damages. ${ }^{2}$ Of course, any explanation of the joint use of liability and

1. On the contrary, Innes (2004) argues that, when accidents are assumed not to be freely observed and detected, regulation can be more cost-effective than liability.

2. Kolstad et al. (1990, p. 888) consider other cases as well. For example " $[\mathrm{t}] \mathrm{he}$ potential inefficiencies of incompatible neighboring property uses - for example, a hospital located next to a noisy, dusty cement-manufacturing plant - are minimized by zoning ordinances (a form of ex-ante regulation) and by simultaneously exposing the externality generator to nuisance liability (a form of ex-post regulation)." See also Schmitz (2000, p. 371). 
J_ID: aler Cust. A_ID: 00000.00 Cadmus Art: aler00000 CVO ID: OP-ALEC190001 - 2019/1/31 - page 3 - \#5

regulation is necessarily based on some limitation or imperfection of either instrument, which prevents it from achieving efficiency when used in isolation. Since the limitations of regulation and liability are generally of a different kind, it is claimed that each instrument can compensate for the limitations of the other one. In this respect, the most common accounts to explain why liability should be supplemented by regulation are that the injurer is judgment-proof or that he can escape liability (Shavell, 1984; Schmitz, 2000; De Geest and Dari-Mattiacci, 2007). The latter problem can, at least in principle, be solved by the application of multiplicative damages (e.g., treble or punitive damages) or by the application of additional ex-post sanctions. However, again, if the injurer does not have sufficient resources, the use of ex-ante instruments such as regulation will be justified.

Judgment proofness, however, is not always a convincing argument. As other authors have pointed out, the injurer is in many circumstances a large firm and the damage is not catastrophic (Innes, 2004). Moreover, in order to solve or at least mitigate the problem, (mandatory) liability insurance may be a viable alternative to regulation.

A different justification for the joint use of regulation and liability is offered by Kolstad et al. (1990), who emphasize the uncertainty regarding the standard of care under a negligence rule. The introduction of regulation, in the form of an ex-ante specification of a standard, reduces such uncertainty because it eliminates the possibility that the courts will err by setting too low a standard. As a consequence, regulation increases the level of care taken by injurers, correcting cases of under-compliance-possibly at the price of exacerbating over-compliance - when liability is used as the sole instrument. $^{3}$

Bhole and Wagner (2008) explain the joint use of regulation and liability when care is multidimensional, with some dimensions observable and others not, and there is uncertainty about conviction. In this case, supplementing liability with regulation can be beneficial even without assuming judgment

3. The hypotheses made in this model on the effect of uncertainty on the injurer's incentive to take care, hence on the benefit of the joint use of regulation and liability, are extensively discussed by Burrows (1999). See also Trebilcock and Winter (1997). In addition, as observed by Schmitz (2000, p. 372), Kolstad et al. do not explain why tort law should be used at all, since in their model efficiency can be secured by regulation alone. 
proofness, since it decreases the expected liability cost of the activity carried out by the injurer. ${ }^{4}$ Finally, Innes (2004) justifies the joint use of liability and regulation on the basis of different enforcement costs for detecting noncompliance relative to accidents (assuming that some accidents are costlessly detected while others are costly to detect).

We propose a novel justification for the joint use of liability and regulation, which relies on a different limitation of liability. In contrast to previous contributions, which focused on unilateral accident models, we consider situations in which: (1) victims have a role in determining the size of the harm, either by taking care or by deciding not to engage in activities which expose them to the risk of being harmed, and (2) victims cannot be fully compensated ex post for the harm suffered in the case of an accident. When victims can avoid harm by adopting defensive behaviors and they are only partially compensated for the harm in the case of an accident, injurers can act strategically and refrain from taking due care, anticipating that victims will be induced to alter their behavior. This will be the case even when judgment proofness is absent, and the expected liability to the injurer equals the expected harm.

The circumstances in which victims play a role in avoiding harm are both common in the literature and prevalent in reality. ${ }^{5}$ The main result in the

4. Another contribution, by Hiriart et al. (2004), builds on and extends the analysis of Shavell (1984), allowing for ex-ante contracting between the injurer and the regulator, and analyze how the injurer can be induced to reveal the information the regulator lacks. The regulator sets the ex-ante first-best regulatory standard, while ex post liability only provides incentives to reveal information.

5. Indeed, in his seminal 1960 article on The Problem of Social Cost, Ronald Coase greatly emphasized the reciprocal nature of externalities, and how harm can be avoided by either party to the interaction. For example, when analyzing the case Bryant v. Lefever C.P.D. 172 (1878-1879) Coase states: "Who caused the smoke nuisance? The answer seems fairly clear. The smoke nuisance was caused both by the man who built the wall and by the man who lit the fires. Given the fires, there would have been no smoke nuisance without the wall; given the wall, there would have been no smoke nuisance without the fires. Eliminate the wall or the fires and the smoke nuisance would disappear." With respect to the other cases analyzed, he says: "Judges have to decide on legal liability but this should not confuse economists about the nature of the economic problem involved. In the case of the cattle and the crops, it is true that there would be no crop damage without the cattle. It is equally true that there would be no crop damage without the crops. The doctor's work would not have been disturbed if the confectioner had not worked his machinery; but the machinery would have disturbed no one if the doctor had not set up his consulting room in that particular place." 
literature regarding "bilateral accidents" is that with full compensation of the victim, a negligence rule dominates a strict liability rule, since the formerbut not the latter-induces an optimal level of care on the part of both the injurer and the victim (a result that extends to the choice of the optimal level of activity by the victim). We depart from the textbook model of bilateral accidents by assuming that, in case of harm, compensation of the victim is only partial, even when the injurer is found liable and properly sanctioned.

With full compensation, when the injurer behaves negligently the victim is equally well off whether the accident occurs or not. Although full compensation is often assumed as a benchmark case, it is an ideal which is rarely achieved. First, in some cases the accident can result in the death of the victim or permanent bodily injury that simply cannot be ex-post compensated for by any (reasonable) monetary amount. This clearly does not imply that people place an infinite value on their lives, nor does it imply that they are reluctant to risk death or serious bodily injury. People indeed take such risks all the time in order to save money or increase their pleasure. For example, people buy cheaper cars with lower safety levels; they engage in risky though enjoyable sports; etc. However, in these cases people expect to benefit from the savings in money and the increase in pleasure while they are alive and well. Compensation under tort law, on the other hand, occurs after an accident has taken place, that is, in a state of the world where it is of less or no value at all to the individual. Therefore, from the perspective of the victim, receiving compensation only when an accident occurs amounts to partial or no compensation. ${ }^{6}$

Second, in less extreme cases, courts usually compensate victims for tangible, easily documented losses (medical costs, lost income, the costs of repairing damaged property, etc.), while they are more reluctant to compensate for intangible losses such as emotional harm, distress, pain, and suffering, which are much more difficult to quantify. More importantly, under many jurisdictions, the legislator imposes caps on noneconomic damage, namely, "pain and suffering" and "loss of life enjoyment." For example, some states in the United States impose such caps in medical

6. The literature on the problems associated with ex-post compensation is large. In a recent paper, Porat and Tabbach (2011) suggested a mechanism of "reverse insurance" under which, in certain cases, people under risk of death will be able to transform ex-post payments to ex-ante payments. 
malpractice cases, while others impose them in any personal injury claim. The caps vary from $\$ 350 \mathrm{k}$ to $\$ 750 \mathrm{k}^{7}$

Finally, bringing a suit involves legal expenses, which in general are not fully recovered. Indeed, it is estimated that legal costs are in the vicinity of a third of the expected judgment. ${ }^{8}$ This is the case under the American rule (each party bears its own legal costs); but even under the English rule, some costs, such as time, effort and stress, are not recovered.

In all these cases, a potential victim will, under a negligence rule, avoid harm if its probability is high and the avoidance costs are sufficiently low. The injurer can therefore opportunistically decide to reduce care, counting on the fact that, in response, many potential victims will take care or avoid any interaction with the injurer. This is a likely scenario if the interaction between the injurer and the victim is sequential, such that the injurer has a first mover advantage; but it can also occur if the interaction between the parties is simultaneous. As a consequence, liability may turn out to be ineffective in securing efficiency.

In such circumstances, regulation can play a critical and constructive role since it can affect the strategic interaction between injurers and victims, ultimately eliciting a different behavior from the victim which restores the effectiveness of liability. In other words, the role of regulation can be to eliminate an equilibrium in which the victim's level of activity is inefficiently low. To accomplish this, it is not necessary that the regulatory standard be set at the optimal level of care required of the injurer, or close to that level; rather, it is sufficient that due to the ex-ante regulation the interaction between the injurer and the victim becomes safe enough to convince the victim to engage in the activity and/or not to take an excessive level of care.

Indeed, a great deal of regulatory activity can be understood as an attempt to reassure the public (i.e., potential victims) about the safety of some

7. Curiously, the damage caps laws all make exceptions for cases involving death and serious bodily injuries, for example, loss of a limb or an organ system. These exception either permit a higher damages cap or eliminate the cap altogether. Thus, in cases where ex-post compensation is impossible there is no cap; while in cases where it is possible there is a cap. Therefore, in both cases the victim is de-facto under-compensated.

8. Consider the standard, one-third, contingency fee (Kritzer, 1998); Shavell (2004, p. 281) estimates that "[I]n the United States the administrative costs of the liability system are large ... for every dollar received by a victim, a dollar or more is spent delivering the dollar to him." 
J_ID: aler Cust. A_ID: 00000.00 Cadmus Art: aler00000 CVO ID: OP-ALEC190001 - 2019/1/31 - page 7 - \#9

interaction with potential injurers. For example, in the United States the EPA (Environmental Protection Agency) provides information to the public about its enforcement strategies and the level of compliance by individual facilities in a specific area; ${ }^{9}$ the FDA (Food and Drug Agency) issues "enforcement reports" and "warning letters," informing the public about food and drug safety; ${ }^{10}$ and so on.

Modeling regulation in our framework leads to interesting and richer results. In particular, we adopt the assumption commonly made in the literature that it is costly to enforce compliance by means of a regulatory standard (enforcement costs). Under this assumption, the regulatory standard with or without liability will fall short of the efficient level of care. However, in such a setting, the joint use of regulation and liability dominates regulation alone and often improves on the use of liability as the exclusive policy instrument. Thus, regulation can be effective even when it is an imperfect and costly social instrument. Indeed, the presence of regulation will make it optimal to set the standard of negligence at a level which would be excessive if liability were used alone. We therefore emphasize the complementarity between the two instruments, in the sense that they are mutually reinforcing instruments used to deter harmful behaviors. In other words, regulation makes liability more effective, while liability makes regulation useful in circumstances in which regulation or liability alone might be a far from optimal instrument to control externalities.

Our analysis contributes not only to the debate regarding the joint use of regulation and liability but also the discussion of the negligence per $s e$ doctrine and the regulatory compliance defense doctrine (or rather its inconclusiveness). A majority of courts in the United States, for example, have adopted the rule that the violation of a regulatory standard constitutes negligence in itself (i.e., it is negligence per se). However, the converse is not true, since compliance with a regulatory standard does not prevent the

9. This information is available under the title "Learn How Facilities Near You are Complying with Environmental Laws" in the EPA website: https://echo.epa.gov.

10. Similar processes occur in other places. For example, the HSE (Health and Safety Executive) in England, issues leaflets "aimed at people who live or work near to a major hazard site" informing them that the agency "has inspectors who specialize in enforcing the law at major hazards sites through a system of inspections" and makes its conclusions available to the public. See http://www.hse.gov.uk/comah/background/essentialinfo.pdf. 
J_ID: aler Cust. A_ID: 00000.00 Cadmus Art: aler00000 CVO ID:

OP-ALEC190001 - 2019/1/31 - page 8 - \#10

8 American Law and Economics Review V0 N1 2019 (000-000)

injurer being deemed negligent. Indeed, generally speaking, regulation is assumed to set only minimum standards, although the rationale for this is not specified (De Geest and Dari-Mattiacci, 2007). As our analysis shows, not only is it efficient to use both liability and regulation, but the efficient level of the regulatory standard should be lower than that of the negligence standard. Thus, in our setting, violating a regulatory standard should be considered negligence, while abiding by it should not be regarded as a defense for liability. Our analysis makes economic sense of this asymmetry.

Our account of the complementarity between regulation and liability is in the spirit of De Geest and Dari-Mattiacci (2007). In their analysis as well, the role of regulation is to eliminate an inefficient outcome (particularly an inefficient local minimum) in which care is suboptimal. Moreover, they consider negligence to be one of the sources of nonconvexity in the injurer's expected cost, giving rise to this kind of inefficiency. Our account is markedly different, however, since what drives the result is the strategic interaction between injurers and victims in a bilateral accidents framework. De Geest and Dari-Mattiacci, and indeed the rest of the literature, consider a unilateral accidents setup and the inefficiency of liability is ultimately due to judgment proofness or a low probability of being sued in case of an accident. $^{11}$

The article proceeds as follows: in Section 2, we set up the formal model and demonstrate the consequences of assuming that compensation is partial. In Section 3, we introduce regulation and discuss how it can complement liability to improve efficiency. In Section 4, we examine how the result is affected by the sequence of the interaction. Section 5 summarizes our results and concludes.

\section{A Model of Negligence and Partial Compensation}

To show how partial compensation of victims can lead to an inefficiently low level of care by the injurer, we consider a version of the standard model

11. Indeed, since De Geest and Dari-Mattiacci (2007) account of the joint use of regulation and liability rests on the classical judgment proofness/disappearing defendant problems, they make clear that their focus is on the puzzle of the negligence per se versus the regulatory compliance defense doctrines. 
J_ID: aler Cust. A_ID: 00000.00 Cadmus Art: aler00000 CVO ID:

OP-ALEC190001 - 2019/1/31 — page 9 - \#11

The Complementary Role of Liability and Safety Regulation

of liability under a negligence rule when the harm also depends on victims' behavior.

A risk neutral firm or individual, henceforth referred to as the injurer, is carrying out an activity, which produces a negative externality on a population of potential risk neutral victims (henceforth simply "victims"). Let the expected harm for the victim be $h(x)$, where $x$ is the cost of care for the injurer: a higher level of care reduces the expected harm at a diminishing rate, that is, $h^{\prime}<0$ and $h^{\prime \prime}>0$. Although we allow the harm to the victim to be probabilistic, risk neutrality makes this aspect irrelevant, so we will speak interchangeably of harm or expected harm.

We assume that victims can avoid the risk of harm. To keep in mind some concrete examples, imagine that the potential injurer is an industrial plant generating harmful emissions in the surrounding area, while victims are neighboring residents; alternatively, consider that the plant pollutes a river and potential victims are families spending their leisure time (e.g., swimming) at the riverside.

Victims, having observed the level of pollution, can avoid harm by moving off the area or giving up the activity, but this, we assume, is associated with a cost $w>0$. Thus, $w$ reflects the opportunity costs for victims of avoiding harm. In light of these examples, we will characterize victims' choice as one of participation. This is a distinctive feature of our model; the standard model of bilateral care considers the choice of the level of care by the victim, and draws a distinction between the choice of care and activity (the latter includes, as a limiting case, the decision to participate); however, in the bilateral care model, a negligence rule copes efficiently with both dimensions of victims' choice. In fact, both in the standard model and in ours, the analysis could be conducted by referring either to the level of care or to participation, where victims' decision to take care in one context corresponds to the decision not to participate in the other. ${ }^{12}$

We assume that $w$ is distributed across the population of potential victims according to a cumulative distribution function $F$. We indicate by $z$ the

12. We implicitly assume that the benefit from participation for the injurer is such that it is never desirable to shut down or relocate the plant. In other words, participation is not a choice variable for the injurer. 
J_ID: aler Cust. A_ID: 00000.00 Cadmus Art: aler00000 CVO ID:

OP-ALEC190001 - 2019/1/31 - page 10 - \#12

10 American Law and Economics Review V0 N1 2019 (000-000)

minimum level of $w$ such that a victim decides to participate, i.e., the opportunity cost of avoiding the interaction with the injurer for the "marginal" victim; hence, $F(z)$ represents the fraction of the population for which the benefit from participation $w$ is less than or equal to $z$, and $N(z)=1-F(z)$ is the fraction of the population participating when the individual expected cost of the externality is equal to $z$. Because $w>0$, we have that $F(0)=0$, hence $0 \leqslant N(z) \leqslant 1$ with $N(0)=1$. Note that, although each victim makes a binary decision whether to participate in the interaction with the injurer or not, with a large population of victims the resulting variable $N(z)$ representing victims' participation in the activity is continuous and differentiable, such that $N^{\prime}(z) \leqslant 0$.

Taking into account the level of participation of potential victims, and normalizing the total population to one, the expected aggregate harm is $N(z) h(x)$ and the social welfare as a function of $x$ and $z$ is:

$$
B(z)-N(z) h(x)-x,
$$

where

$$
B(z)=\int_{z}^{\infty} w d F(w)
$$

is victims' aggregate benefit (or forgone cost of moving elsewhere) from the activity which exposes them to the externality. By maximizing (1) with respect to $x$ and $z$, we determine the socially optimal level of care by the injurer and the optimal participation of potential victims. It is convenient for the analysis that follows to solve the problem in two stages, defining the benefit for victims at the optimal level of participation as a function of the level of care $x$ :

$$
W(x) \equiv \max _{z}\{B(z)-N(z) h(x)\} .
$$

Because $B^{\prime}(z)=-F^{\prime}(z) z=N^{\prime}(z) z$, we have that the first-order condition for the maximization (3) is $N^{\prime}(z)(z-h(x))=0$, hence an interior solution is $z=h(x)$. This has a straightforward interpretation: given that a victim will decide to participate if and only if the resulting benefit $w$ is larger than the cost, the optimal level of participation is achieved when victims are 
J_ID: aler Cust. A_ID: 00000.00 Cadmus Art: aler00000 CVO ID: OP-ALEC190001 - 2019/1/31 - page 11 - \#13

exposed to the full effect of the externality $h(x) .{ }^{13}$ When this is the case, victims' net benefit is maximized and equal to $W(x)$, and

$$
W(x)=B(h(x))-N(h(x)) h(x) \quad W^{\prime}(x)=-N(h(x)) h^{\prime}(x) .
$$

Therefore, when we take into account the cost of care $x$, and participation is optimal given $x$, social welfare can be expressed as

$$
W(x)-x
$$

We assume the maximization of (5) has an interior solution: the optimal level of care $x^{*}$ is larger than zero and satisfies the first-order condition $W^{\prime}\left(x^{*}\right)=1$, or

$$
-N\left(h\left(x^{*}\right)\right) h^{\prime}\left(x^{*}\right)=1
$$

Intuitively, efficiency requires that the resulting marginal reduction in total harm equals the marginal cost of care. However, it is worth emphasizing that there is no warranty the function $W(x)$ is always concave, hence the first-order condition is not sufficient.

\subsection{Negligence with Full Compensation}

A standard result in the economic analysis of liability is that, when due care is set to the efficient level, namely $x^{*}$, and the compensation is equal to harm, a negligence rule induces the injurer to take efficient care and the victims (as the residual bearers of the expected harm) to choose the efficient level of activity $z^{*}=h\left(x^{*}\right)$. This is easily shown in our framework. When care is below the level of due care $\left(x<x^{*}\right)$, in case of accident the injurer will be liable and will pay to victims damages equal to the harm $h(x)$. Victims, observing a level of care $x<x^{*}$ and knowing they will be fully compensated for the harm suffered, will participate as long as $w>0$, hence participation will be $N(0)=1$. On the other hand, with $x \geqslant x^{*}$ the number of victims is irrelevant for the injurer, who is not held liable for the effects

13. Second-order conditions for maximization are verified if $N^{\prime}(z) \neq 0$ at $z=$ $h(x)$, as in this case the second-order derivative is $N^{\prime \prime}(z)(z-h(x))+N^{\prime}(z)=N^{\prime}(z)<0$. 
J_ID: aler Cust. A_ID: 00000.00 Cadmus Art: aler00000 CVO ID:

OP-ALEC190001 - 2019/1/31 - page 12 - \#14

12 American Law and Economics Review V0 N1 2019 (000-000)

of his decision. Therefore, the injurer will choose $x$ to minimize

$$
\begin{cases}h(x)+x & x<x^{*} \\ x & x \geqslant x^{*} .\end{cases}
$$

For $x<x^{*}$ we have

$$
x^{*}<N\left(z^{*}\right) h\left(x^{*}\right)+x^{*} \leq N\left(z^{*}\right) h(x)+x \leq h(x)+x,
$$

where we have used the fact that $x^{*}$ minimizes $N\left(z^{*}\right) h(x)+x$ and that $N(h(x)) \leq 1$. Because there is no point choosing $x>x^{*}$ under a negligence rule, the optimal choice will be $x^{*}$. On the other hand, when the injurer is not negligent, victims will fully bear the consequences of the accident, hence their participation will be defined by the condition $z^{*}=h\left(x^{*}\right)$.

\subsection{Negligence with Partial Compensation}

The equilibrium turns out to be markedly different when the compensation of the victim is partial. In this case, an accident is costly to the victim even when the injurer is negligent and fully liable. We assume that $h(x)$ reflects the social and the private harm to the victim from the accident; ${ }^{14}$ damages paid by the injurer are equal to social harm, namely, $h(x)$, while $q$ will be the fraction of the expected harm that the victim bears after taking into account compensation. The most straightforward way to interpret this framework is to imagine that part of the damages paid by the injurer — namely: $q h(x)$ — goes to a third party instead of the victim — say the government. ${ }^{15}$ In the exterme case that the victim receives no compensation at all $(q=1)$ the framework reflects ex-post, negligence-based

14. In case the accident results in the death of the victim, it may be that the two quantities do not coincide; as a consequence, people under risk of death may take a inefficiently high level of care to avoid an accident. Note however that if there is a divergence between the social and the private harm, even negligence with full compensation will be inefficient. By assuming that the social and private harm from an accident do not diverge we largely disregard these possibilities. For a thorough discussion of these issues, refer to Porat and Tabbach (2011).

15. A setting compatible with this interpretation is that victims sue the injurer with probability less than one. In this case, the answer may be to supplement damages with a fine or a public sanction, so that the expected damages (plus sanction) paid by the injurer are larger and are aligned to the expected cost $h(x)$, while compensation to the victim is only a fraction of this amount. 
J_ID: aler Cust. A_ID: 00000.00 Cadmus Art: aler00000 CVO ID:

OP-ALEC190001 - 2019/1/31 - page 13 - \#15

The Complementary Role of Liability and Safety Regulation

public sanction, creating a separation between liability and compensation. Another interpretation, that we emphasized in the introduction, follows when the accident results in the death or serious bodily injuries of the victim. It is true that the victim can internalize the value of the compensation received by heirs, but in general we expect that such compensation is lower, possibly much lower, than the amount that could make the victim indifferent between incurring and not incurring the accident (provided that such amount exists and is finite). ${ }^{16}$

Throughout most of our analysis, we assume a specific sequence of the interaction between the injurer and potential victims: first the injurer decides the level of care $x$, and on the basis of this choice (which victims can observe) victims decide whether to participate or not. Note that such specification was not necessary in the case of full compensation, as the choice of the injurer was independent of victims' behavior (i.e., the injurer had a dominant strategy to take efficient care). We will return to this point in Section 4, where we will analyze the consequence of assuming that the interaction between the parties is simultaneous.

We analyze the effect of liability considering that the standard of negligence is set at level $x_{n}$ and that damages are set equal to the actual harm. Note that the standard can be set at $x_{n}=x^{*}$, but it is useful to present the case of a generic standard of negligence $x_{n} \leqslant x^{*}$.

When $x<x_{n}$, victims' participation will be determined by the condition $z=q h(x)$. Anticipating victims' behavior, the injurer will choose $x$ to minimize:

$$
\begin{cases}N(q h(x)) h(x)+x & x<x_{n} \\ x & x \geqslant x_{n} .\end{cases}
$$

16. Formally, we can imagine that the victim has a state-dependent utility function, one for "no accident" and another for "accident"; and $1-q$ is the ratio between the value of compensation in the second and in the first case. Therefore, when the injurer pays damages equal to social harm, the victim who receives the compensation in the state of the world where the accident took place discounts them by $1-q$. This interpretation is consistent with Cook and Graham (1977), although they assume that individuals are risk averse. 
J_ID: aler Cust. A_ID: 00000.00 Cadmus Art: aler00000 CVO ID:

OP-ALEC190001 - 2019/1/31 - page 14 - \#16

The marginal effect of an increase in $x$ at $x<x_{n}$ is

$$
h^{\prime}(x)\left[N(q h(x))+q h(x) N^{\prime}(q h(x))\right]+1 ;
$$

this is higher than it was in the case full compensation, i.e., $h^{\prime}(x)+1$ (recall that $h^{\prime}<0,0 \leqslant N \leqslant 1$ and $N^{\prime} \leqslant 0$, so the term in brackets in (10) is less than one). Moreover, while $1+h^{\prime}(x)$ is always negative for $x \leqslant x^{*},{ }^{17}$ the expression (10) can be positive, ${ }^{18}$ implying that the cost for the injurer decreases as $x$ is reduced. The intuition is simple: on the one hand a reduction in care by the injurer increases the expected harm for each potential victim, but on the other hand it induces a larger share of potential victims to avoid the risk of being harmed; the net effect may be a reduction in the aggregate harm the injurer will be held liable for.

This implies that for some low levels of precautions the saving in precaution costs may exceed the expected cost of being sanctioned. In other words, there may be values $x<x_{n}$ such that

$$
N(q h(x)) h(x)+x<x_{n}
$$

Let $Q\left(x_{n}\right)$ be the set of values $x$ for which condition (11) is satisfied. If $Q\left(x_{n}\right)$ is non-empty, all the values belonging to this set will be preferred by the injurer to complying with the standard of negligence $x_{n}$. To be satisfied, condition (11) requires that, when the injurer takes an insufficient level of care $\left(x<x_{n}\right)$, the benefit from participation is lower than the expected uncompensated cost for a large enough share of the population; or, equivalently, the uncompensated cost is high enough that most of the population will prefer to leave and refrain from any interaction with the injurer. Clearly, for given $x_{n}$, condition (11) will be more likely satisfied the larger is the share of the uncompensated harm, $q$.

That condition (11) is satisfied for some $x$ is not just a theoretical possibility. Indeed, this will certainly be the case when setting the minimum possible level of care $(x=0)$ induces a very low level of participation, as with $N(q h(0))$ approaching zero the LHS of the inequality is driven down

17. Since $x^{*}$ is defined by condition (6) and $N \geqslant 1$, it is $h^{\prime}\left(x^{*}\right)+1<0$; from $h^{\prime \prime}>0$ follows that $h^{\prime}(x)+1<0$ for all $x<x^{*}$. negative

18. Observe that when $-q h(x) N^{\prime}(q h(x))>N(q h(x))$ the term in brackets is 
J_ID: aler Cust. A_ID: 00000.00 Cadmus Art: aler00000 CVO ID:

OP-ALEC190001 - 2019/1/31 - page 15 - \#17

The Complementary Role of Liability and Safety Regulation

to zero as well. One can imagine that this occurs when the probability of an accident at low levels of care is not trivial, and the accident will result in death or serious bodily injuries of the victim. ${ }^{19}$

For future reference, it is useful to introduce some additional definitions. When $Q\left(x_{n}\right)$ is nonempty, we define $\beta\left(x_{n}\right)$ as the supremum of $Q\left(x_{n}\right)$, i.e., the lowest value $x$ which is larger than all values in $Q\left(x_{n}\right)$; in other words, $\beta\left(x_{n}\right)$ has the property that for all $x>\beta\left(x_{n}\right)$ we have $x_{n} \leqslant N(q h(x)) h(x)+x$, and no value $x^{\prime}<\beta\left(x_{n}\right)$ has the same property. Because $h$ and $N$ are continuous, $\beta\left(x_{n}\right)$ is the value $x$ which solves $N(q h(x)) h(x)+x=x_{n}$ (more precisely, because we cannot be sure the solution is unique, it is the maximum value of $x$ where this equality is satisfied when its LHS is increasing).

Clearly, $\beta\left(x_{n}\right)<x_{n}$, and $\beta\left(x_{n}\right)$ is increasing in $x_{n}$. The latter property follows from the fact that, as $x_{n}$ decreases, the inequality in condition (11) becomes more restrictive, hence the set $Q\left(x_{n}\right)$ shrinks: with $x_{n}^{\prime}<x_{n}$, we have $Q\left(x_{n}^{\prime}\right) \subset Q\left(x_{n}\right) \cdot{ }^{20}$ When $\beta$ is differentiable, monotonicity implies that $\beta^{\prime}\left(x_{n}\right)>0$; note however that continuity and differentiability of $\beta$ are not warranted everywhere, as $N(q h(x)) h(x)+x$ is not necessarily monotonic. ${ }^{21}$

If $Q\left(x_{n}\right)$ is nonempty, the injurer's optimal choice when the negligence standard is set at $x_{n}$ will be to select the level of care $\hat{x}$ where $N(q h(x)) h(x)+x$ is minimized for $x \in Q\left(x_{n}\right) .{ }^{22}$ We define $\bar{x}$ as

$$
\bar{x}=N(h(\hat{x})) h(\hat{x})+\hat{x}>\hat{x}
$$

where the inequality follows from the fact that $N(h) h \geqslant 0$. We can prove the following

19. Note that condition (11) will never be satisfied for $q=0$ when $x_{n} \leqslant x^{*}$ (i.e., with full compensation of the harm), as in that case $N=1$ and the condition reduces to $h(x)+x>x_{n}$. We have $x_{n} \leqslant x^{*}<N\left(z^{*}\right) h\left(x^{*}\right)+x^{*} \leqslant N(h(x)) h(x)+x<h(x)+x$ for all $x$.

20. On the one hand $\beta\left(x_{n}^{\prime}\right)$ belongs to $Q\left(x_{n}\right)$, hence $\beta\left(x_{n}^{\prime}\right) \leqslant \beta\left(x_{n}\right)$; on the other, by continuity it is $N\left(q h\left(\beta\left(x_{n}\right)\right)\right) h\left(\beta\left(x_{n}\right)\right)+\beta\left(x_{n}\right)=x_{n}>x_{n}^{\prime}$, hence $\beta\left(x_{n}\right) \notin Q\left(x_{n}^{\prime}\right)$, from which follows that $\beta\left(x_{n}^{\prime}\right)<\beta\left(x_{n}\right)$.

21. It can be proved, however, that $\beta$ is a lower semi-continuous function, i.e., its value near $x$ is either close to $\beta(x)$ or greater than $\beta(x)$.

22. Under the assumption of continuity of $h$ and $N$, such a minimum (which might be $\hat{x}=0$, the minimum level of care) always exists. 
J_ID: aler Cust. A_ID: 00000.00 Cadmus Art: aler00000 CVO ID:

OP-ALEC190001 - 2019/1/31 - page 16 - \#18

Lemma 1 Assume there exists some value $x_{n}$ such that $Q\left(x_{n}\right)$ is nonempty, that the function $N(q h(x)) h(x)+x$ is minimized in $Q\left(x_{n}\right)$ at $\hat{x}$ and define $\bar{x}$ from (12). Then,

(1) for any $x_{n}^{\prime}$ such that $Q\left(x_{n}^{\prime}\right)$ is nonempty, the function $N(q h(x)) h(x)+$ $x$ is minimized in $Q\left(x_{n}^{\prime}\right)$ at $\hat{x}$;

(2) $Q\left(x_{n}^{\prime}\right)$ is non-empty if and only if $x_{n}^{\prime}>\bar{x}$.

Proof. To prove (a), consider first $x_{n}^{\prime}<x_{n}$ such that $Q\left(x_{n}^{\prime}\right)$ is nonempty: as stated above, it will be $Q\left(x_{n}^{\prime}\right) \subset Q\left(x_{n}\right)$, hence the minimum in $Q\left(x_{n}^{\prime}\right)$ cannot be lower than the minimum in $Q\left(x_{n}\right)$; on the other hand, because $\hat{x}$ is such that $N(q h(\hat{x})) h(\hat{x})+\hat{x}<N(q h(x)) h(x)+x$ for all $x \in Q\left(x_{n}\right)$, the inequality is satisfied for all $x \in Q\left(x_{n}^{\prime}\right)$, hence $\hat{x}$ belongs to $Q\left(x_{n}^{\prime}\right)$; it follows that $\hat{x}$ is the minimum in $Q\left(x_{n}^{\prime}\right)$. Consider instead that $x_{n}^{\prime}>x_{n}$ such that $Q\left(x_{n}^{\prime}\right)$ is nonempty: because $Q\left(x_{n}\right) \subset Q\left(x_{n}^{\prime}\right), \hat{x}$ belongs to $Q\left(x_{n}^{\prime}\right)$; moreover, for $x \in Q\left(x_{n}^{\prime}\right) \backslash Q\left(x_{n}\right)$ it is $N(q h(\hat{x})) h(\hat{x})+\hat{x} \geqslant x_{n}>\hat{x}$, hence $\hat{x}$ is the minimum in $Q\left(x_{n}^{\prime}\right)$.

To prove $(b)$, consider that, because of $(a)$, when $Q\left(x_{n}^{\prime}\right)$ is nonempty it has a minimum in $\hat{x}$, hence $\hat{x} \in Q\left(x_{n}^{\prime}\right)$. This implies that $\bar{x}=N(q h(\hat{x})) h(\hat{x})+\hat{x}<$ $x_{n}$. On the other hand, if $x_{n}^{\prime}>\bar{x}$, then $N(q h(\hat{x})) h(\hat{x})+\hat{x}=\hat{x}<x_{n}^{\prime}$, hence condition (11) is satisfied at $\hat{x}$, and $Q\left(x_{n}^{\prime}\right)$ is nonempty.

The Lemma states that, when $Q\left(x_{n}\right)$ is nonempty for some $x_{n}$, no standard of negligence above a certain threshold $\bar{x}$ will induce the injurer to take due care (as defined by the standard itself). When $x_{n}>\bar{x}$, the injurer will select the level of care $\hat{x}$, which does not depend on the specific $x_{n}$.

We will assume throughout our analysis that $Q\left(x^{*}\right)$ is nonempty: following the Lemma, this is equivalent to assuming there is $\bar{x}$ such that $Q\left(x_{n}\right)$ is nonempty for all $x_{n}>\bar{x}$ and $x^{*}>\bar{x}$.

In Figure 1, we provide a graphical illustration of the expected costs for the injurer under specific assumptions on the shapes of the relevant functions and on the values of the parameters. Namely, we assume that $q=2 / 3, h(x)=40 e^{-x}$, and $F$ is a log-normal distribution, with mean and standard deviation on the log scale both equal to 1.25 (the values have been chosen to make the graph as clear and readable as possible).

The injurer's expected cost $N(q h(x)) h(x)+x$ is represented by the blue line. For reference, we have included in the graph the expected cost when 


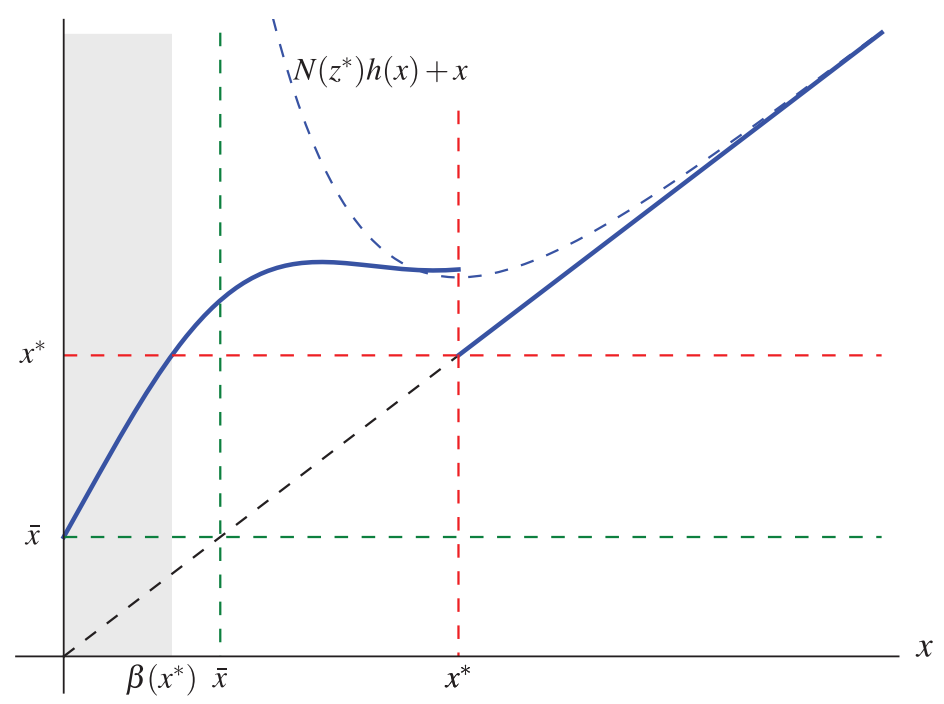

Figure 1. Simulation with $h(x)=40 e^{-x}$ and $\ln w \sim \mathcal{N}(1.25,1.25)$.

the population of victims is fixed at its optimal level, whose expression is $N\left(z^{*}\right) h(x)+x$ (dashed curve $)^{23}$; its minimum identifies the socially optimal level of care $x^{*}$ (dashed curve).

The graph shows that the set $Q\left(x^{*}\right)$ - the shaded area-corresponds to the interval between zero and $\beta\left(x^{*}\right)$, where the expected cost for the injurer is lower (while for all $x>\beta\left(x^{*}\right)$ it is higher) than $x^{*}$. It is clear that in this specific case the expected cost is minimized at $x=0$. At such a low level of care, in fact the minimum possible level, the population of potential victims will be small in size, and the aggregate expected harm will be low. Although expected harm is minimized, social welfare will not be maximized at this level, as social welfare takes into account the forgone benefits of the victims who were discouraged from participating in the activity.

In our example, if the negligence standard is set at $x^{*}$ - or at any other level $x_{n}$ such that $Q\left(x_{n}\right)$ is nonempty - the injurer will choose a level of care equal to zero. However, setting the efficient standard and letting the injurer

23. It should be noted that this curve does not correspond to the relevant expected cost curve of the injurer under a negligence rule with full compensation, as described by (7). 
J_ID: aler Cust. A_ID: 00000.00 Cadmus Art: aler00000 CVO ID:

OP-ALEC190001 - 2019/1/31 - page 18 - \#20

choose a lower level of care and be negligent is not optimal in general. More generally, there is no point setting a standard $x_{n} \geqslant \bar{x}$, such that $Q\left(x_{n}\right)$ is nonempty and the injurer selects $\hat{x}$ : because with $x_{n}<\bar{x}$ the corresponding set $Q\left(x_{n}\right)$ is empty (see Lemma 1 above) it is always possible to induce the injurer to select any level between zero and $\bar{x}$ (including $\hat{x}$, as $\hat{x}<\bar{x}$ ) by choosing such level directly as standard of negligence. Therefore, if $Q\left(x^{*}\right)$ is nonempty, the optimal standard of negligence will be the level which maximizes social welfare $W(x)-x$ in the interval $[0, \bar{x}] .{ }^{24}$

We summarize all the discussion above in

Proposition 2 Consider a bilateral accident model where a negligent injurer is liable for harm but victims' compensation in case of an accident is partial. Then, if the set $Q\left(x^{*}\right)$ is not empty (i.e., condition (11) is satisfied for some $x$ when $x_{n}=x^{*}$ ), the optimal standard of negligence will be in the interval $[0, \bar{x}]$, with $\bar{x}<x^{*}$, implying an inefficiently low level of care and, consequently, an inefficiently low level of participation/activity of victims.

Proposition 2 states that, under plausible circumstances, a negligence regime where the standard of care is set at the efficient level can induce a suboptimal level of care by the injurer (possibly a corner solution where the injurer takes the minimum possible care). Consequently, there will be an inefficiently low level of participation by the potential victims. The reason in a nutshell is that since victims are not fully compensated for the harm, the injurer can strategically reduce the level of care, anticipating that the victims will respond by avoiding the interaction; as a result, the actual liability for the injurer will be lower than the cost of abiding by the negligence standard.

From the logic of the argument, it also follows that an increase in liability in case of an accident may not solve the problem, as the injurer can still strategically count on the fact that it will be in the interest of the victims to avoid the harm by choosing to refrain from the interaction with the injurer. This possibility depends of course on the effect of an increased risk of accident on participation: if a subgroup of the population of victims derives a large benefits from the interaction, or if for some other reasons

24. Because we cannot be sure that $W(x)-x$ is increasing in this interval, we do not know in general whether the optimal level is zero, $\bar{x}$ or some intermediate level. 
J_ID: aler Cust. A_ID: 00000.00 Cadmus Art: aler00000 CVO ID:

OP-ALEC190001 - 2019/1/31 - page 19 - \#21

The Complementary Role of Liability and Safety Regulation

it is bound to interact with the injurer, punitive damages or other solutions involving accident-based sanctions could in principle increase the expected liability for negligent injurers sufficiently, and therefore induce them to take efficient care. ${ }^{25}$

Another possible solution, that the reader should always bear in mind, is to fully compensate the victim for harm. However, as we pointed out in the introduction, in certain cases involving death and serious bodily injuries, ex-post compensation is simply impossible. In other cases, undercompensation may be a result of a deliberate policy choice, as in the case of damages cap or nonrecovery for (all) legal expenses. ${ }^{26}$

In the next sections, we will discuss the effect of supplementing expost liability with ex-ante regulation. We can make the argument that the regulator (in the U.S. for example, the federal regulator) cannot alter the policy leading to under-compensation of victims, but it can contemplate the use of regulation.

\section{Regulation as a Complement to Liability}

We discuss now the effect of supplementing ex-post liability with ex-ante regulation. By regulation, we mean direct imposition of a safety standard whose observance is monitored and enforced irrespective of the occurrence of an accident and is backed by a sanction. Therefore, regulation requires setting the regulatory standard $\left(x_{r}\right)$ along with the enforcement policy, characterized by the intensity of monitoring and the sanction in case of violation. Because punishment does not depend on the frequency or number of accidents, regulation is immune from the problem affecting liability described in the previous section.

25. That an increase in accident-contingent sanctions is not necessarily a solution is proved by considering that in this case the expected cost (9) would become $N(q h(x)) \operatorname{th}(x)+x$ where $t>1$ is a multiplicative factor applied to the ordinary sanction. This would make the condition (11) more stringent, but would not eliminate the possibility of the inefficient equilibrium: for example, if $N(q h(x))=0$ for $x=0$ goes to zero, the inequality is satisfied whatever the value of $t$.

26. A further possibility, which we do not discuss in this article, is compensating victims for the "loss of enjoyment" in case the injurer did not take due care and victims refrained from participating in the activity. Although such a rule can induce the efficient outcome, it involves compensating victims even when there is no accident. This is not the way the tort system generally operates, and we are not aware of such a rule in any legal system. In any case, this solution is beyond the scope of this article. 
J_ID: aler Cust. A_ID: 00000.00 Cadmus Art: aler00000 CVO ID:

OP-ALEC190001 - 2019/1/31 - page 20 - \#22

In the present framework, the joint use of liability and regulation can be understood as a method to eliminate the potential weaknesses of liability emphasized above. It is apparent from our analysis that liability could be markedly more effective if the injurer is forced to choose a sufficiently high level of care: knowing that the probability of an accident is not too high, potential victims would participate in the interaction with the injurer; therefore, the injurer could no longer count on victims' avoidance and would be induced by liability to take due care. Since ex ante regulation does not depend on the link between care, participation and actual occurrence of an accident, its introduction can be an effective way to reassure and convince victims that the injurer will take a sufficiently high level of care.

In this context, the function of regulation is not to induce the injurer to take the optimal level of care, but rather to make the inefficient equilibrium unattractive for the injurer. To this end, it is sufficient that regulation induces the injurer to take a level of care such that the expected cost for the negligent injurer is larger than the costs of abiding by the negligence standard, $x^{*}$.

In the previous section we defined $\beta\left(x_{n}\right)$ as the level of care above which, taking into account the reaction of the victims, the injurer's expected cost is larger than $x_{n}$. Therefore, we can state more specifically that the purpose of regulation is to induce the injurer to take a level of care $x \geqslant \beta\left(x_{n}\right)$. This result will be achieved if a regulatory standard $x_{r}$ equal to or larger than $\beta\left(x_{n}\right)$ is set, and sanctions (at a level such that the injurer will prefer to abide by the regulatory standard) are imposed when such a standard is not met, regardless of the occurrence of an accident. In other words, regulation can be used to induce the injurer to choose his level of care in the interval between $\beta\left(x^{*}\right)$ and $x^{*}$.

We summarize this point in the following:

Proposition 1 In the bilateral accident model of Proposition 2, consider a standard of negligence $x_{n}>\bar{x}$ (i.e., such that $Q\left(x_{n}\right)$ is non-empty). If such a regime is supplemented by ex-ante regulation with a minimum standard $x_{r}$ such that $\beta\left(x_{n}\right) \leqslant x_{r} \leqslant x_{n}$, the unique equilibrium involves the injurer taking a level of care equal to $x_{n}$.

Proof. The proof follows straightforwardly from the fact that, when the standard of regulation $x_{r}$ is enforced, the choice of the injurer is restricted 
J_ID: aler Cust. A_ID: 00000.00 Cadmus Art: aler00000 CVO ID:

OP-ALEC190001 - 2019/1/31 - page 21 - \#23

The Complementary Role of Liability and Safety Regulation

to be a level $x \geqslant x_{r}>\beta\left(x_{n}\right)$. From the definition of $\beta\left(x_{n}\right)$ follows that for any $x>\beta\left(x_{n}\right)$ the expected cost for the injurer will be no lower than $x_{n}$.

From this directly follows that it is possible to reach the efficient level of care $x^{*}$ and participation $z^{*}=h\left(x^{*}\right)$ by supplementing negligence (with standard $x_{n}=x^{*}$ ) with regulation (with standard $x_{r}$ with $\beta\left(x_{n}\right) \leqslant x_{r}<x^{*}$ ).

Proposition 1 emphasizes the complementary role of negligence and regulation, but does not say much about the optimal value of $x_{r}$. Moreover, one may wonder whether negligence is necessary at all, given that we could obtain $x^{*}$ simply by setting $x_{r}=x^{*}$. Finally, we could ask if, having to rely on regulation, $x_{n}=x^{*}$ is still an optimal solution. To this end, we introduce the costs of regulation in a more detailed way.

\subsection{Enforcement Costs}

Regulation is costly. The simple reason is that it requires the regulator to monitor the behavior of potential injurers and verify that safety standards are respected. We will assume, therefore, as it is also customary in the literature, that regulation involves the cost of inspecting (possibly probabilistically) the behavior of the injurer and imposing a sanction in case the standard is violated. The regulator, therefore, needs to choose a regulatory standard, $x_{r}$, whose violation may trigger a sanction, a level of enforcement and the level of the sanction in case a violation is detected. To enforce the regulatory standard, the regulator needs to monitor the behavior of the injurers and it can do so probabilistically (we assume that an inspection occurs with no errors such that noncompliance is always identified). The cost of enforcing and punishing noncompliance is increasing in the probability $p$ that a violation is detected; we assume for simplicity that the cost is linear in $p$ (in case of a population of potential injurer, we can think of $p$ as the percentage of injurers which are inspected), hence it is equal to $\delta p$ with $\delta>0$.

We will assume that the sanction is a monetary sanction and therefore its imposition is socially costless. Because inspecting is costly, the enforcement cost will be minimized by setting the sanction to its maximum level $S$, which can be interpreted as the highest level of the sanction prescribed by the legislator or as the maximum feasible resources of potential injurers. It follows that the cost minimizing probability of inspection is the lowest $p$ which satisfies: 
J_ID: aler Cust. A_ID: 00000.00 Cadmus Art: aler00000 CVO ID:

OP-ALEC190001 - 2019/1/31 - page 22 - \#24

$$
x_{r} \leqslant p S \text {. }
$$

that is the expected sanction must not be lower than the cost of the required level of care. Observe that, when (13) is satisfied, the injurer will abide by the regulatory standard $x_{r}$, while he will violate the regulatory standard and choose a level of care equal to zero otherwise (assuming of course the absence of a negligence regime). ${ }^{27}$ Because the minimum probability necessary to induce a given regulatory standard $x_{r}$ is $p=x_{r} / S$, the corresponding enforcement cost (namely, the minimum enforcement cost, when the sanction is set to its maximum value $S$ ) will be

$$
\delta p=\delta x_{r} / S=c x_{r}
$$

hence, the enforcement cost is (linearly) increasing in the standard, with $c=\delta / S$ the marginal cost of increasing the regulatory standard. ${ }^{28}$

The reader may wonder why similar costs (namely, the costs of enforcing the negligence system) were not taken into account in our previous analysis and whether they should be explicitly introduced here. Enforcement of negligence, to be sure, requires some monitoring too, when an accident has taken place, in order to establish whether the injurer was negligent. However, traditionally, the costs of enforcing negligence were not always taken into account in the tort literature. ${ }^{29}$ More importantly, it stands to reason that, for a given level of deterrence, the enforcement costs of regulation would be higher than the costs of enforcing negligence, for two main reasons. First, the nature of the accident itself may provide guidance to what went wrong, and may point out whether the injurer failed to take due care,

27. The reason, of course, is that from the perspective of the injurer, if the standard is not met, taking care involves only costs and does not relieve the injurer from punishment; hence, there is no point in taking any level of care larger than the minimum (zero). We are implicitly assuming that the sanction does not depend on the magnitude of the deviation from the regulatory standard.

28. A further reason why the cost of enforcement can be increasing in the standard is that a higher level of care generally involves a larger number of (possibly different) actions and checks by the injurer; this may imply that a higher standard requires that the marginal cost $c$ is itself increasing in the standard $x_{r}$. We will disregard this possibility, which could however reinforce the conclusions reached below on the relative benefits of regulation and negligence. 2007).

29. Indeed, most of the standard, classical papers disregard such costs (see Shavell, 
J_ID: aler Cust. A_ID: 00000.00 Cadmus Art: aler00000 CVO ID:

OP-ALEC190001 - 2019/1/31 - page 23 - \#25

The Complementary Role of Liability and Safety Regulation

making detection easier. To illustrate, consider a set of cameras to control traffic laws in a certain geographic area. It is one thing to monitor all cameras all the time, it is another thing to check a camera at a specific location. The costs for the ex ante control will presumably be much larger than the cost of verifying ex post only when an accident actually occurred. ${ }^{30}$

Second, in our model we assumed that victims observe the behavior of the injurer, and they condition their participation on the injurer's level of precautions. Therefore, if the injurer takes due care, he will not be considered negligent, and the victim will never sue, so enforcement costs will be zero. Note that the fact that the victim observes the behavior of the injurer does not mean that he can prove it in court without costs. Indeed, there is a difference between observability and verifiability. In our analysis, we essentially assume that observing the behavior of the injurer is costless, while verifying it in court is costly. ${ }^{31}$

To summarize, we will consider that, although ex post inspection by a court has a positive cost, the enforcement cost of negligence will be zero in the equilibrium in which the injurer takes due care.

\subsection{The Optimum with Regulation Alone}

Before discussing the optimal use of regulation and negligence, let us analyze the case in which regulation is the only instrument available. As shown above, given that the cost of enforcement is minimized by setting the highest possible sanction, the choice of the regulator reduces to the choice of the regulatory standard, and the resulting enforcement cost is given by $c x_{r}$.

Because under regulation victims are not compensated for the harm suffered, they will participate when the expected benefit from participation is

30. Consider also the inspection of a plant: ex ante verification will be very complex and time consuming, as it requires that inspectors check that all parts potentially subject to wear have been replaced within the prescribed time in order to prevent a rupture; it is much simpler to check when the part which broke was last replaced once a malfunction has materialized.

31. An alternative to this assumption is that inspections always takes place ex post (i.e., after an accident occurred) to detect negligence and trigger victims' legal actions. This corresponds to the case extensively analyzed by Shavell (2013), where it is argued that even in this case ex post monitoring is less costly than ex ante monitoring through regulation. The reason is that ex post monitoring is conditional to a probability of accident which has been reduced by the precautions taken by the injurer. 
J_ID: aler Cust. A_ID: 00000.00 Cadmus Art: aler00000 CVO ID:

OP-ALEC190001 - 2019/1/31 - page 24 - \#26

24 American Law and Economics Review V0 N1 2019 (000-000)

higher than the expected harm (as stated by condition $z=h(x)$ ). Therefore social welfare, to be maximized by the regulator choosing $x_{r}$, is given by

$$
W\left(x_{r}\right)-x_{r}-c x_{r} .
$$

This expression for the objective function differs from the one we considered in the case of negligence in Section 2 for the last term $c x_{r}$, representing the enforcement cost. As we said above, $c$ can be interpreted as the marginal cost of increasing the regulatory standard. Observe that from the fact that $x^{*}$ maximizes $W(x)-x$ follows that $W\left(x^{*}\right)-x^{*}>W(x)-x$ for all $x$; hence, for all $x>x^{*}$, it must be

$$
W\left(x^{*}\right)-x^{*}-c x^{*}>W(x)-x-c x .
$$

Therefore, the optimal regulatory standard, $x_{r}^{*}$ must be such that $x_{r}^{*} \leqslant x^{*}$. Because we assumed that the $W(x)$ is differentiable around $x^{*}$, the inequality must be strict, ${ }^{32}$ that is, $x_{r}^{*}<x^{*}$. In words, the regulatory standard is lower than the efficient level of care.

AQ5 In Figure 2, using the same functional form and parameters' values of the previous section, we plot the curves $W(x)-x-c x$ for different values of $c$. Note that the optimal regulatory standard $x_{r}^{*}$ can correspond to a local maximum at a level slightly lower than $x^{*}$, but it could also correspond to a global maximum at zero when $c$ is sufficiently large (in our example, this is the case with $c=0.65$ ). The highest (dashed) line represents the case of zero enforcement cost, whose maximum corresponds to the social optimum $x^{*}$. For the convenience of the reader, we summarize our conclusions in the following

Proposition 2 In a bilateral accident model (described above) the optimal regulatory standard $x_{r}^{*}$ falls short of the efficient level of care, that is, $x_{r}^{*}<x^{*}$.

\subsection{The Optimum with Regulation and Negligence}

We now turn to the optimal joint use of negligence and regulation. From Proposition 1, we know that when regulation is used along with negligence,

32. From the fact that $W^{\prime}\left(x^{*}\right)=1$ follows that a marginal reduction of $x$ below $x^{*}$ through regulation reduces social welfare as represented by (15). 
J_ID: aler Cust. A_ID: 00000.00 Cadmus Art: aler00000 CVO ID: OP-ALEC190001 - 2019/1/31 - page 25 - \#27

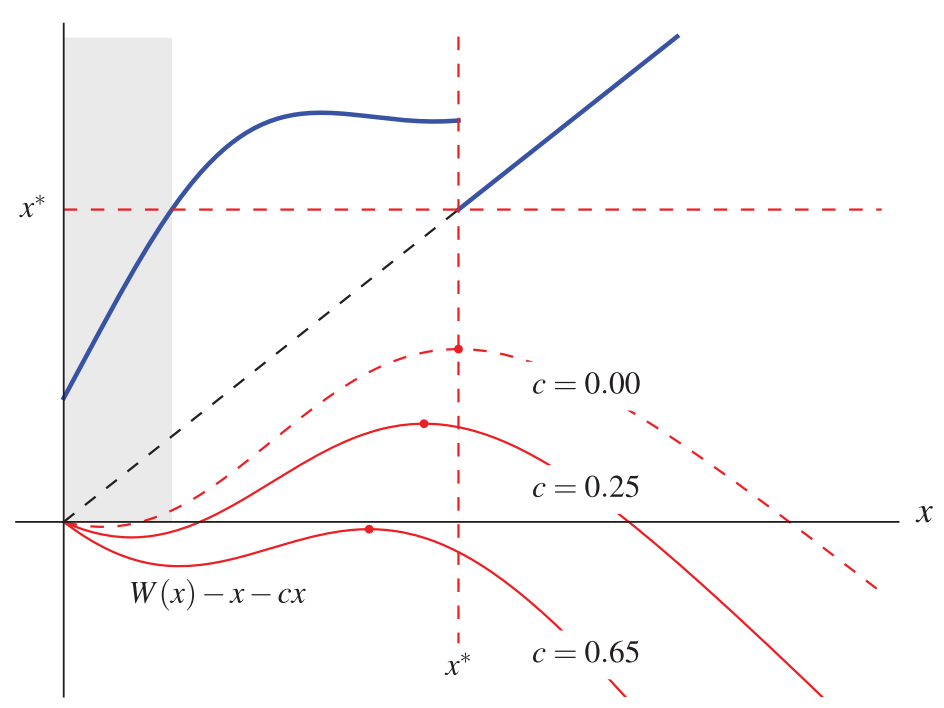

Figure 2. Optimal Level of Regulation Under Different Hvnotheses about $c$ (Simulation with $h(x)=40 e^{-x}$ and $\ln w \sim \mathcal{N}(1.25,1.25)$ ).

it is possible to set a standard of negligence higher than $\bar{x}$ (i.e., a standard such that $Q\left(x_{n}\right)$ is non-empty). More specifically, in order to enforce a standard $x_{n}>\bar{x}$, negligence must be supplemented by regulation with standard $x_{r} \geqslant \beta\left(x_{n}\right)$. Considering that regulation is costly, with the cost increasing in $x_{r}$, the optimal solution will be to set $x_{r}$ at its lowest level $\beta\left(x_{n}\right)$, and social welfare will be

$$
W\left(x_{n}\right)-x_{n}-c \beta\left(x_{n}\right) .
$$

From $\beta\left(x_{n}\right)<x_{n}$ follows that (17) is higher than the social welfare when the same standard $x_{n}$ is enforced using only regulation (which is given by Equation (15) when we set $x_{r}=x_{n}$ ). This means that, for any $x_{n}>\bar{x}$, a solution with regulation alone is dominated by negligence supplemented by regulation.

We can summarize our results in the following

Proposition 3 Enforcing a level of care $x>\bar{x}$ with negligence (with standard $x_{n}=x$ ) supplemented by regulation (with standard $x_{r}=\beta(x)<x$ ), 
J_ID: aler Cust. A_ID: 00000.00 Cadmus Art: aler00000 CVO ID:

OP-ALEC190001 - 2019/1/31 - page 26 - \#28

is less costly and therefore more efficient than enforcing it with regulation alone (with standard $x_{r}=x$ ).

On the other hand, any level of care $x \leqslant \bar{x}$ can be enforced by negligence alone, with standard $x_{n}=x$. The optimal standard $x_{n}^{*}$, and therefore the optimal policy, is the level of $x_{n}$ maximizing

$$
\begin{cases}W\left(x_{n}\right)-x_{n}-c \beta\left(x_{n}\right) & \text { for } x_{n}>\bar{x}, \text { i.e., when } Q\left(x_{n}\right) \text { is nonempty } \\ W\left(x_{n}\right)-x_{n} & \text { for } x_{n} \leqslant \bar{x} .\end{cases}
$$

Depending whether the optimal level $x_{n}^{*}$ is higher or lower than $\bar{x}$, the optimal solution will involve respectively the joint use of negligence and regulation or reliance on negligence alone.

Of course, in either case social welfare will be lower than in the case of negligence with full compensation, i.e., it will be lower than $W\left(x^{*}\right)-x^{*}$. Moreover, it can be easily proved that the standard of negligence $x_{n}^{*}$ will be lower than $x^{*}$. This is trivially true if $x_{n}^{*} \leqslant \bar{x}<x^{*}$; when instead $x_{n}^{*}>\bar{x}$, it follows from the fact that $W(x)-x$ is maximized at $x^{*}$ and from that $\beta(x)$ is increasing in $x$ that $x_{n}^{*}<x^{*} .{ }^{33}$

We also observe that the lower is $c$, the more likely it is that the optimal solution is $x_{n}^{*}>\bar{x}$. Indeed, we can prove that

Proposition 4 When $Q\left(x^{*}\right)$ is nonempty, there exists a marginal cost $c^{*}>0$ of enforcing the standard of regulation such that, for all $c \leqslant c^{*}$, the optimal solution involves the joint use of negligence with standard $x_{n}^{*}$ and regulation with standard $\beta\left(x_{n}^{*}\right)<x_{n}^{*}$.

Proof. Let $x^{* *}$ be the level of care which maximizes $W(x)-x$ for $x \leqslant \bar{x}$; because of the constraint, welfare is lower at $x^{* *}$ than at $x^{*}$, hence there exists $c^{*}>0$ such that: $W\left(x^{* *}\right)-x^{* *}=W\left(x^{*}\right)-x^{*}+c^{*} \beta\left(x^{*}\right)$. For any $c \leqslant c^{*}$, the function $W(x)-x-c \beta(x)$ is decreasing at $x^{*}$, because $\beta$ is

33. From the fact that $W\left(x^{*}\right)-x^{*} \geqslant W(x)-x$ and from monotonicity of $\beta$ follows that, for all $x>x^{*}, W\left(x^{*}\right)-x^{*}-c \beta\left(x^{*}\right)>W(x)-x-c \beta(x)$. On the other hand, because $\beta$ is a strictly increasing function of $x$ and $W^{\prime}\left(x^{*}\right)=1$, the function $W(x)-x-c \beta(x)$ must be increasing at $x^{*}$, so that $x^{*}$ cannot be a maximum. 
J_ID: aler Cust. A_ID: 00000.00 Cadmus Art: aler00000 CVO ID: OP-ALEC190001 - 2019/1/31 - page 27 - \#29

increasing; hence, such function admits a maximum ${ }^{34}$ at $x_{n}^{*}<x^{*}\left(x_{n}\right.$ is the maximum when the $\operatorname{cost}$ is $c$ ). For all $x \leqslant \bar{x}$ we have:

$$
\begin{aligned}
& W(x)-x-c \beta(x)<W(x)-x \leqslant \\
& W\left(x^{* *}\right)-x^{* *}=W\left(x^{*}\right)-x^{*}-c^{*} \beta\left(x^{*}\right)< \\
& W\left(x^{*}\right)-x^{*}-c \beta\left(x^{*}\right)<W\left(x_{n}^{*}\right)-x_{n}^{*}-c \beta\left(x_{n}^{*}\right) .
\end{aligned}
$$

We see that $x_{n}^{*}$ maximizes (18) and that it must belong to the interval $\left[\bar{x}, x^{*}\right]$, i.e., it implies the joint use of negligence and regulation.

Proposition 4 indicates that the joint use of regulation and liability will be optimal when the cost of regulation $c$ is not too high. It is interesting to check whether the standard of negligence when negligence is jointly used with regulation is lower or higher than the standard of regulation when the latter is used alone. In other words, whether by utilizing negligence with regulation we achieve a higher level of care then if we restrict ourselves to regulation alone (recall that the joint use of regulation and liability implies that the negligence standard is necessarily higher than when negligence is used alone). Unfortunately it is not possible to answer this question in general: we expect that $x_{n}^{*}>x_{r}^{*}$ if a marginal increase in $x_{n}^{*}$ is less costly than a marginal increase in $x_{r}^{*}$, and this will be the case when $\beta^{\prime}<1,{ }^{35}$ but we cannot be sure that the latter condition is always satisfied.

There are definitely cases where $\beta\left(x_{n}^{*}\right)<x_{r}^{*}$, meaning that the regulatory standard decreases once negligence is taken into account (this is the case of our simulation, see Figure 2). However, the case of $x_{n}^{*}>x_{r}^{*}$ involves the possibility that $\beta\left(x_{n}^{*}\right)>x_{r}^{*}$. If this were the case, the (optimal) joint use of negligence and regulation would bring about an increase in the regulatory standard as compared to the case of regulation alone. Thus, regulation and negligence will be complements also in the sense that the latter makes the former more effective. The intuition behind this result is that, with negligence, increasing the standard of regulation has a higher benefit in inducing

34. The existence of a maximum relies on the fact that the function is upper semi-continuous (see footnote 21).

35. The first-order conditions for the maximization of social welfare are respectively $W^{\prime}\left(x *_{n}\right)=1+c \beta\left(x_{n}^{*}\right)$ and $W^{\prime}\left(x_{r}^{*}\right)=1+c$. 
J_ID: aler Cust. A_ID: 00000.00 Cadmus Art: aler00000 CVO ID:

OP-ALEC190001 - 2019/1/31 - page 28 - \#30

a higher level of care by the injurer because it contributes to increase the standard of negligence as well.

\section{Sequential vs. Simultaneous Interaction, and Coordination}

In presenting our model (see e.g., Proposition 2), we have specified that potential victims observe the injurer's level of care before deciding whether to participate in the activity; in other words, we assumed a sequential game. This is a reasonable assumption in many cases, especially when a single injurer faces several potential victims. We have shown that, when the injurer moves first, like the leader in a Stackelberg game, the optimal strategy may be to exert care at a very low level, so that (a large number of) victims will respond by giving up the interaction with the injurer.

However, this is not the only way to conceptualize the interaction between the injurer and the victims. In an alternative setting, victims may be required to take their decisions without knowing the level of care taken by the injurer. In this case, the parties move simultaneously and their interaction is more complex, resulting in a more intricate analysis.

The equilibrium with standard of negligence $x_{n}$ will be characterized by victims choosing the optimal level of participation $z=q h(x)$ for $x<x_{n}$, and $z=h(x)$ for $x \geqslant x_{n}$, and by injurers minimizing, for given $z$,

$$
\begin{cases}N(z) h(x)+x & x<x_{n} \\ x & x \geqslant x_{n} .\end{cases}
$$

In this case, assuming that the negligence standard is set at $x^{*}$, the efficient solution will be a Nash equilibrium. ${ }^{36}$ However, when $Q\left(x^{*}\right)$ is nonempty, the possibility arises that other equilibria exist with $x \in Q\left(x^{*}\right)$, i.e., such that (11) is satisfied. We may have either an internal solution at the level $x$ where the first-order condition from the minimization of (20) is satisfied,

36. This is easily proved: when care is $x^{*}$, the optimal level of victims' participation will be $z^{*}=h\left(x^{*}\right)$; on the other hand, $x^{*}$ minimizes $N\left(z^{*}\right) h(x)+x$, hence $x^{*}<N\left(z^{*}\right) h\left(x^{*}\right)+x^{*}<N\left(z^{*}\right) h(x)+x$ for all $x<x^{*}$ : choosing $x^{*}$ is optimal for the injurer when participation is $z^{*}$. 
J_ID: aler Cust. A_ID: 00000.00 Cadmus Art: aler00000 CVO ID: OP-ALEC190001 - 2019/1/31 - page 29 - \#31

so that the equilibrium condition is:

$$
N(q h(x)) h^{\prime}(x)+1=0
$$

or a corner solution at the minimum level of care $x=0$, with $N(q h(0)) h^{\prime}(0)$ $+1>0$. At either equilibrium, the injurer finds it optimal to provide a suboptimal level of care rather than the level $x^{*}$. This will occur, for instance, when $N(q h(0))=0$, as in this case the first-order conditions are satisfied at $x=0$ (corner solution), along with condition (11). In this case, the inefficient equilibrium will be the same identified for the sequential case.

Therefore, when the injurer and victims make their choices simultaneously, liability can be inefficient in the weaker sense that it cannot uniquely guarantee the efficient equilibrium. ${ }^{37}$ In other words, it cannot rule out the risk that an inefficient equilibrium where the injurer is negligent will be implemented. In that case, regulation, as explained in Section 3, can play the constructive role of eliminating the inefficient equilibrium, and induce the efficient equilibrium as a unique solution. Because the role of regulation is to coordinate the players to the efficient equilibrium, it stands to reason that once regulation fulfills its purpose, it can be eliminated. This would be particularly desirable, if regulation itself is costly, as assumed in Section 3.

For completeness one can consider also the consequences of letting the victims move first. In this case, regulation can be redundant, as efficiency can be reached uniquely by liability alone. The reason is that victims, by choosing the optimal level of participation, will motivate the injurer to take due care; there's no incentive for the injurer to take less than optimal care once victims have chosen a high level of participation. Observe that victims will not have a strategic interest to engage excessively in the activity, as long as the due care standard for the injurer is set efficiently, namely, at $x^{*}$. The reason, of course, is that the moment the injurer takes due care, he is not considered negligent, and therefore the residual expected harm is born by the victims. ${ }^{38}$ Thus, there is asymmetry regarding the sequence of the game, where the injurer as a leader strategically causes the victims to bear

37. The multiplicity of equilibria in case of partial compensation of the victim in a different setting (alternative care model) is extensively discussed by D'Antoni and Tabbach (2014).

38. Thus, there is asymmetry regarding the sequence of the game, where the injurer as a leader strategically causes the victims to bear a larger share of the costs of 
J_ID: aler Cust. A_ID: 00000.00 Cadmus Art: aler00000 CVO ID:

OP-ALEC190001 - 2019/1/31 - page 30 - \#32

a larger share of the costs of avoiding the accident, while the victims, due to the nature of negligence, cannot do that in our settings.

However, both in the case of a simultaneous game and in the case victims move first, a relevant aspect is whether victims can coordinate their behavior. Indeed, if coordination is not possible and the expectation is that a large enough share of the victims will choose not to participate, so that the injurer will not be motivated to take care, it may be in the interest of most victims not to participate. As a matter of fact, with one injurer and many victims, the injurer has some advantage in piloting expectations, and can probably take actions to induce the inefficient equilibrium - e.g., by making clear to the victims that no care will be taken and encourage them to take defensive measures. In this case, regulation can still play a role in affecting victims' expectations and help them coordinate to the equilibrium where they (optimally) participate and the injurer takes care, ruling out the possibility of the inefficient equilibrium.

\section{Concluding Remarks}

In this article, we have analyzed the control of harmful behavior through the joint use of ex-ante regulation and ex-post liability in a bilateral accidents setting. We have shown that, whenever the compensation of the victim is only partial, negligence liability can be inefficient when used as the only instrument to correct the externality. The reason for this is that injurers can strategically adopt a suboptimal level of care, in the anticipation that victims will refrain from participating in the risky activity and thus avoid harm. Although in the law and economics textbooks it is clearly stated that perfect compensation is a condition for negligence to be optimal, ${ }^{39}$ to our knowledge the implication of relaxing that assumption have not been explored before. We show that, when compensation is partial, a nonconvexity in the injurer's expected cost function can result in an inefficient equilibrium.

In such circumstances, ex-ante regulation can play a constructive and complementary role in securing an efficient outcome. By increasing the

avoiding the accident, while the victims, due to the nature of negligence, cannot do the same.

39. See, e.g., Cooter and Ulen (2008), where it is emphasized that negligence induce efficient care in a bilateral setting only under the assumption of "perfect compensation." 
J_ID: aler Cust. A_ID: 00000.00 Cadmus Art: aler00000 CVO ID:

OP-ALEC190001 - 2019/1/31 - page 31 - \#33

care taken by injurers, it reassures potential victims about the safety of the interaction with the injurer, thereby increasing their participation level. As a result, the inefficient equilibrium becomes unattractive for injurers, and the liability system kicks in, inducing injurers to take (second-best) optimal care and victims to participate optimally in the risky interaction.

It is worthwhile clarifying the sense in which we describe regulation as a complement to liability and vice versa. The term "complementarity" is being used here in the conventional sense, such that the use of one instrument improves the effectiveness of the other. ${ }^{40}$ Thus, on the one hand, the use of regulation makes liability more effective in inducing injurers to take care; on the other hand, the use of liability makes the limitations of regulation, namely its cost, less of a concern, and in certain circumstances it may even justify a higher regulatory standard. An example would be when the optimal standard of the regulation-only solution is zero. This differentiates our account of the joint use of liability and regulation from many others (with the notable exception of De Geest and Dari-Mattiacci, 2007), in which regulation and liability are treated as substitutes, i.e., the use of one instrument makes the other less necessary, or as independent instruments, i.e., each one deals with a different problem.

Another way to understand why negligence is ineffective is to highlight the inability of victims to coordinate and commit to engaging in the risky interaction with the injurer. Indeed, if it were clear that the victims will participate, it would be in the best interest of the injurer to exert due care, since in that case the cost of care would be less than the expected damages from not taking care. In this regard, regulation can be thought of as a credible coordination device to be used by victims, as was demonstrated in the case of simultaneous interaction.

The analysis and results of this article also make economic sense of the asymmetry between the legal doctrines of negligence per se and the inconclusiveness of a regulatory compliance defense. In our analysis, efficiency requires that the regulatory standard be set below the negligence

40. The notion that two activities are complementary when doing more of one of them increases the returns to doing more of the another is broader than the usual definition of complementarity among inputs found in microeconomics textbooks, and is usually attributed to Edgeworth. 
J_ID: aler Cust. A_ID: 00000.00 Cadmus Art: aler00000 CVO ID:

OP-ALEC190001 - 2019/1/31 - page 32 - \#34

32 American Law and Economics Review V0 N1 2019 (000-000)

standard and that both systems be operative. Therefore, abiding by a regulatory standard should not prevent a finding of negligence; and, at the same time, not abiding by a regulatory standard can indeed be clear evidence of negligence.

Two final remarks regarding strict liability and care technology are in order.

First, we have focused on negligence rather than strict liability. This is partly because negligence dominates strict liability when the victim's compensation is full and unconditional. This is because the former, but not the latter, encourages victims to choose an optimal level of care or an optimal level of activity/participation. Therefore, it seems less relevant to analyze a liability rule that is inefficient even under ideal conditions. Indeed, as long as victims receive partial compensation, they will have an incentive to participate excessively in the interaction with the injurer and therefore, it will be impossible to induce both the injurers and the victims to behave efficiently, even by supplementing strict liability with regulation of the injurer. Nevertheless, our analysis is still relevant in the limiting case in which victims receive absolutely no compensation at all. In such a case, strict liability amounts to "double liability," and its characteristics are similar, though not identical, to those of negligence. For example, if the injurer moves first (as in our main analysis), we expect to have the same (inefficient) equilibrium, and if both parties move simultaneously, the efficient outcome is an equilibrium but not a unique one. In these cases, regulation can play a constructive role in eliminating the inefficient equilibrium and thus induce the efficient outcome.

Second, it is worthwhile emphasizing the assumption implicit in our analysis regarding care taken by the injurer and the victims. In our setting, care by the injurer and participation by the victims are complements in determining the expected harm. This is a natural assumption when the victim's decision is whether or not to participate in an activity. However, the analysis could be carried over to the case in which victims decide how much care they take when engaging in an activity that exposes them to the possibility of being harmed by the injurer. In this more general case, the relation between the injurer's care and the victim's care can go in either direction: they can be either complements or substitutes in how they affect the expected harm. In this regard, increasing participation can be equated 
J_ID: aler Cust. A_ID: 00000.00 Cadmus Art: aler00000 CVO ID: OP-ALEC190001 - 2019/1/31 - page 33 - \#35

to taking less care, so that the setting we have discussed in this article corresponds to one of substitutability between the levels of care chosen by the parties. It should be clear from our analysis that the results do not apply in the case of complementarity. The reason for this, in short, is that the injurer gains no benefit by strategically taking less care, since this would merely induce the victims to take less rather than more care.

\section{References}

Bhole, Bharat and Jeffrey Wagner. 2008. "The Joint Use of Regulation and Strict Liability with Multidimensional Care and Uncertain Conviction," 28 International Review of Law and Economics 123-32.

Burrows, Paul. 1999. "Combining Regulation and Legal Liability for the Control of External Costs," 19 International Review of Law and Economics 227-44.

Coase, Ronald H. 1960. "The Problem of Social Cost," 3 Journal of Law and Economics 1-44.

Cook, Philip J. and Daniel A. Graham. 1977. "The Demand for Insurance and Protection: the Case of Irreplaceable Commodities," 91 Quarterly Journal of Economics 143-56.

Cooter, Robert and Thomas Ulen. 2008. Law and Economics, 5th edn., AddisonWesley,

D'Antoni, Massimo and Avraham D. Tabbach. 2014. "Inadequate Compensation and Multiple Equilibria," 38 International Review of Law and Economics $33-47$.

De Geest, Gerrit and Giuseppe Dari-Mattiacci. 2007. "Soft Regulators, Tough Judges," 15 Supreme Court Economic Review 119-40.

Hiriart, Yolande, David Martimort, and Jerome Pouyet. 2004. "On the Optimal Use of Ex Ante Regulation and Ex Post Liability," 84 Economics Letters 231-35.

Innes, Robert. 2004. "Enforcement Costs, Optimal Sanctions, and the Choice Between Ex-Post Liability and Ex-Ante Regulation," 24 International Review of Law and Economics 29-48.

Kolstad, Charles D., Thomas S. Ulen, and Gary V. Johnson. 1990. "Ex Post Liability for Harm vs. Ex Ante Safety Regulation: Substitutes or Complements?" 80 American Economic Review 888-901.

Kritzer, Herbert M. 1998. "The Wages of Risk: The Returns of Contingency Fee Legal Practice," 47 DePaul University Law Review

Porat, A. and A. Tabbach. 2011. "Willingness to Pay, Death, Wealth, and Damages," 13 American Law and Economics Review 45-102.

Schmitz, Patrick W. 2000. "On the Joint Use of Liability and Safety Regulation," 20 International Review of Law and Economics 371-82. 
J_ID: aler Cust. A_ID: 00000.00 Cadmus Art: aler00000 CVO ID:

OP-ALEC190001 - 2019/1/31 - page 34 - \#36

34 American Law and Economics Review V0 N1 2019 (000-000)

Shavell, Steven. 1984. "A Model of the Optimal Use of Liability and Safety Regulation," 15 Rand Journal of Economics 271-80.

Shavell, Steven. 2004. Foundations of Economic Analysis of Law. Cambridge, MA: Harvard University Press.

Shavell, Steven. 2007. "Liability for Accidents," in A. Mitchell Polinsky and Steven Shavell, eds., Handbook of Law and Economics, Vol. 1, chapter 2, 139-82. Amsterdam: Elsevier.

Shavell, Steven. 2013. "A Fundamental Enforcement Cost Advantage of the Negligence Rule over Regulation," 42 The Journal of Legal Studies 275-302.

Trebilcock, Michael and Ralph A. Winter. 1997. "The Economics of Nuclear Accident Law," 17 International Review of Law and Economics 215-43. 